\title{
A prospective interventional cohort study of 175 patients treated by the SpineCor orthosis, following the Scoliosis Research Society Criteria
}

\author{
C Coillard*, A Circo, CH Rivard \\ From 9th International Conference on Conservative Management of Spinal Deformities - SOSORT 2012 \\ Annual Meeting \\ Milan, Italy. 10-12 May 2012
}

\section{Background}

The mainstay of the conservative treatment still remains the orthosis, which was demonstrated to provide a reduction of curve progression, possibly a decrease in the need for surgery, and sometimes a correction of the existing deformity. The effectiveness of the SpineCor orthosis compared with the natural history of the disease has already been shown for milder and moderate curves[1].

\section{Aim}

To provide confirmation on the demonstrated effectiveness of the Dynamic SpineCor orthosis for adolescent idiopathic scoliosis, following the standardized criteria proposed by the SRS Committee on Bracing and Nonoperative Management[2], and to confirm the stability of the results two years after the end of the treatment.

\section{Method}

From 1993 to 2011, 390 patients treated using the SpineCor orthosis respected the criteria for inclusion recommended by the SRS committee. 198 have a definitive outcome, and 175 have at least 2 years of follow-up.

Assessment of brace effectiveness included; 1) percentage of patients who have 5 degree or less curve progression, and the percentage of patients who have 6 degree or more progression at skeletal maturity, 2) percentage of patients who have had surgery recommended/undergone before skeletal maturity, 3) percentage of patients with curves exceeding 45 degree at maturity (end of treatment) and 4) 2-years follow-up beyond maturity to determine

Ste-Justine Hospital, Montreal, Canada

C 2013 Coillard et al; licensee BioMed Central Ltd. This is an Open Access article distributed under the terms of the Creative Commons Attribution License (http://creativecommons.org/licenses/by/2.0), which permits unrestricted use, distribution, and reproduction in any medium, provided the original work is properly cited. the percentage of patients who subsequently underwent surgery.

\section{Results}

At two years post skeletal maturity, successful treatment (correction $>5$ degree or stabilization \pm 5 degree) was achieved in 100 patients of the 175 patients (57.2\%) from the time of the fitting of the SpineCor orthosis to the 2 years follow-up point. 41 immature patients $(23.4 \%)$ required surgical fusion.(34 while receiving treatment and 5 in the follow-up period).

\section{Conclusions}

The SpineCor orthosis is effective for the treatment of adolescent idiopathic scoliosis. Positive outcomes are maintained after the weaning of the orthosis, since $86.1 \%$ of the patients stabilized or corrected their Cobb angle. Moreover, out of the $86.1 \%, 11.7 \%$ of the patients still had correction of their Cobb angle 2 years after the end of the treatment.

Published: 3 June 2013

\section{References}

1. Coillard C, Vachon V, Circo AB, Beausejour M, Rivard CH: Effectiveness of the SpineCor brace based on the new standardized criteria proposed by the scoliosis research society for adolescent idiopathic scoliosis. J Pediatr Orthop 2007, 27(4):375-379.

2. Richards BS, Bernstein RM, D'Amato CR, Thompson GH: Standardization of criteria for adolescent idiopathic scoliosis brace studies: SRS Committee on Bracing and Nonoperative Management. Spine 2005, 30(18):2068-2075, discussion 2076-2067.

doi:10.1186/1748-7161-8-S1-047

Cite this article as: Coillard et al:: A prospective interventional cohort study of 175 patients treated by the SpineCor orthosis, following the Scoliosis Research Society Criteria. Scoliosis 2013 8(Suppl 1):047. 